\title{
Transcriptomic analysis reveals insights into deep-sea adaptations of the dominant species, Shinkaia crosnieri (Crustacea: Decapoda: Anomura), inhabiting both hydrothermal vents and cold seeps
}

\author{
Jiao Cheng ${ }^{1,3}$, Min Hui ${ }^{1,3}$ and Zhongli Sha ${ }^{1,2,3,4^{*}}$ (i)
}

\begin{abstract}
Background: Hydrothermal vents and cold seeps are typical deep-sea chemosynthetically-driven ecosystems that allow high abundance of specialized macro-benthos. To gather knowledge about the genetic basis of adaptation to these extreme environments, species shared between different habitats, especially for the dominant species, are of particular interest. The galatheid squat lobster, Shinkaia crosnieri Baba and Williams, 1998, is one of the few dominant species inhabiting both deep-sea hydrothermal vents and cold seeps. In this study, we performed transcriptome analyses of S. crosnieri collected from the lheya North hydrothermal vent (HV) and a cold seep in the South China Sea (CS) to provide insights into how this species has evolved to thrive in different deep-sea chemosynthetic ecosystems.

Results: We analyzed 5347 orthologs between HV and CS to identify genes under positive selection through the maximum likelihood approach. A total of 82 genes were identified to be positively selected and covered diverse functional categories, potentially indicating their importance for $S$. crosnieri to cope with environmental heterogeneity between deep-sea vents and seeps. Among 39,806 annotated unigenes, a large number of differentially expressed genes (DEGs) were identified between HV and CS, including 339 and 206 genes significantly up-regulated in HV and CS, respectively. Most of the DEGs associated with stress response and immunity were upregulated in $\mathrm{HV}$, possibly allowing $\mathrm{S}$. crosnieri to increase its capability to manage more environmental stresses in the hydrothermal vents.

Conclusions: We provide the first comprehensive transcriptomic resource for the deep-sea squat lobster, $\mathrm{S}$. crosnieri, inhabiting both hydrothermal vents and cold seeps. A number of stress response and immune-related genes were positively selected and/or differentially expressed, potentially indicating their important roles for $S$. crosnieri to thrive in both deep-sea vents and cold seeps. Our results indicated that genetic adaptation of S. crosnieri to different deep-sea chemosynthetic environments might be mediated by adaptive evolution of functional genes related to stress response and immunity, and alterations in their gene expression that lead to different stress resistance. However, further work is required to test these proposed hypotheses. All results can constitute important baseline data for further studies towards elucidating the adaptive mechanisms in deep-sea crustaceans.
\end{abstract}

Keywords: Galatheidae, Deep-sea adaptation, Comparative transcriptome, Positive selection, Differential expression

\footnotetext{
* Correspondence: shazl@qdio.ac.cn

'Laboratory of Marine Organism Taxonomy and Phylogeny, Institute of

Oceanology, Chinese Academy of Sciences, Qingdao 266071, China

${ }^{2}$ Laboratory for Marine Biology and Biotechnology, Qingdao National

Laboratory for Marine Science and Technology, Qingdao 266237, China

Full list of author information is available at the end of the article
}

(c) The Author(s). 2019 Open Access This article is distributed under the terms of the Creative Commons Attribution 4.0 International License (http://creativecommons.org/licenses/by/4.0/), which permits unrestricted use, distribution, and

reproduction in any medium, provided you give appropriate credit to the original author(s) and the source, provide a link to the Creative Commons license, and indicate if changes were made. The Creative Commons Public Domain Dedication waiver (http://creativecommons.org/publicdomain/zero/1.0/) applies to the data made available in this article, unless otherwise stated. 


\section{Background}

The discoveries of chemosynthetic ecosystems (hydrothermal vents, cold seeps and other deep-sea sites of organic enrichment) have revolutionized our perceptions of life in the deep sea [1]. Hydrothermal vents and cold seeps constitute energy hotpots on the seafloor that share high concentrations of reduced chemicals as energy source utilized by chemoautotrophic bacteria, supporting a high-biomass benthic community far from the euphotic zone [2]. Despite sharing the similar process of chemosynthesis, hydrothermal vents seem more severe and ephemeral than cold seeps as environments for organisms [3]. Hydrothermal vents are patchily distributed in mid-ocean ridges, volcanic arcs and back-arc spreading centers, where they are usually ephemeral and not strongly sedimented. In comparison, more stable and sediment-hosted cold seeps occur at both passive continental margins and subduction zones, where more stable communities lead to species with extreme lifespan [4]. Active emitting sites in hydrothermal vents discharge more dissolved organic chemicals, including methane, hydrogen sulfide and other hydrocarbon-rich fluids, than oozing sites in cold seeps [3]. On the other hand, vent effluents are also known to enrich in heavy metals [5], reaching such high concentrations that is considered to be toxic to living organisms [6]. Apart from geological settings and the chemicals used for energy, hydrothermal vents have an appreciable temperature gradient from the maximum of emitting hot water (ca. $350^{\circ} \mathrm{C}$ ) to the minimum of ambient cold water (2 ${ }^{\circ} \mathrm{C}-3{ }^{\circ} \mathrm{C}$ ), but no such gradient in cold seeps [7].

Despite their habitat differences, deep-sea vent and seep communities share more than $20 \%$ species occurring in the same region, indicating their genetic connectivity [8]. Beyond biogeographic issues, another hot topic in deep-sea biology is how those animals have adapted to the extreme environmental conditions including high hydrostatic pressure, variable temperatures and high levels of toxins. Advances in sequencing technologies over the last few years have allowed researchers to uncover molecular processes important for fauna that can survive under such inhospitable environments in the deep sea. Within deep-sea chemosynthetic ecosystems, particularly hydrothermal vents, transcriptome sequencing has been applied in several deep-sea macro-benthos to explore the genetic basis of their adaptation to extreme environmental conditions, including mussels $[9,10]$, worms [11, 12] and shrimps [13-15]. Among them, a high-throughput sequencing analysis was conducted in the cold seep mussel Bathymodiolus platifrons, in which genes related to immune function and detoxification were identified to be responsible for extreme environmental adaptation [15]. In addition, a comparative transcriptome analysis of the alvinocaridid shrimp Rimicaris sp. indicated that most of the genes involved in sulfur metabolism and detoxification were up-regulated in the shrimps taken directly from the vent site compared with those maintained under normal laboratory condition [16]. These studies greatly extend our understanding on the molecular mechanisms of deep-sea adaptations. To gain more knowledge about the genetic basis of adaptation to deep-sea chemosynthetic environments, shared species across different kinds of deep-sea chemosynthetic habitats, especially for the dominant species, are of particular interest $[17,18]$.

The galatheid squat lobster, Shinkaia crosnieri Baba and Williams, 1998, is first described from hydrothermally active areas of the Bismarck Archipelago and the Okinawa Trough in the west Pacific Ocean [19]. Chan et al. [20] also mentioned this species as the first known deep-sea hydrothermal animal in Taiwan. Besides inhabiting many deep-sea hydrothermal vents, $S$. crosnieri has also been considered the dominant member of the fauna at a deep-sea cold seep on the Formosa Ridge off the coast of southwestern Taiwan in the South China Sea [21]. Recent molecular studies revealed high levels of genetic differentiation between the vent and seep populations for $S$. crosnieri, but not for the mussel $B$. platifrons, and suggested relatively low degree of tolerance to environmental heterogeneity of $S$. crosnieri in comparison to B. platifrons [22]. Therefore, S. crosnieri may serve as an ideal model to study how marine organisms have adapted to different deep-sea chemosynthetic environments.

Given the environmental heterogeneity between deep-sea vents and cold seeps, we hypothesized that the species co-distributed in both environments likely have evolved survival strategies to adapt to their respective habitats. In order to reveal the possible differences of molecular basis of $S$. crosnieri in adaptation to hydrothermal vents and cold seeps, we conducted a high-throughput transcriptome analysis of the squat lobsters collected from the Iheya North hydrothermal vent in Okinawa Trough (HV) and a cold seep in the South China Sea (CS). With these datasets, we aim to trace signatures of positive selection in $S$. crosnieri during adaptation to deep-sea vents and seeps, and discover genes and pathways that are differentially expressed between HV and CS. By comparing the sequence characteristics and gene expression between the vent and seep $S$. crosnieri, we also hope to identify genes that potentially contributed to the survival of deep-sea squat lobster in both environments, thus providing insights into how this species has evolved to thrive in different deep-sea chemosynthetic ecosystems. These results can constitute important baseline data with which to gain insights into the adaptation process to deep-sea extreme environments in macro-organisms.

\section{Methods}

\section{Sample collection and RNA isolation}

Specimens of S. crosnieri were collected using suction samplers mounted on remotely operated vehicle (ROV) 'Fa Xian' from the Iheya North hydrothermal vent in Okinawa Trough $\left(126^{\circ} 58.82^{\prime} \mathrm{E}, 27^{\circ} 47.44^{\prime} \mathrm{N}, \sim 983.5 \mathrm{~m}\right)$ in April 2014, and a cold seep in the South China Sea 
$\left(119^{\circ} 28.544^{\prime} \mathrm{E}, 22^{\circ} 11.57^{\prime} \mathrm{N}, \sim 1133.4 \mathrm{~m}\right)$ in July 2015 during the cruises conducted by the scientific research vessel KEXUE. Once board, the squat lobsters were immediately frozen in liquid nitrogen (sacrificed) and stored at $-80^{\circ} \mathrm{C}$ until RNA extraction. Every effort was made to minimize animal suffering. Three adult individuals from each sampling site were randomly selected as biological replications. Total RNA for the whole bodies of six $S$. crosnieri individuals was extracted separately using the mirVana $^{\text {Tw }}$ miRNA Isolation Kit without phenol (Ambion, Inc., Austin, TX, USA) and treated with RNase free DNaseI according to manufacturer's instructions. The quality of RNA samples was detected by $1 \%$ agarose gel electrophoresis stained with GelRed (Biotium, Fremont, CA, USA) and further confirmed by spectrophotometer (NanoDrop ND-1000, NanoDrop Technologies, Wilmington, DE, USA).

\section{Library construction, sequencing and de novo assembly}

A total amount of $1.5 \mu \mathrm{g}$ RNA per sample was used to construct cDNA library. Six libraries were constructed using NEBNext $^{\circ}$ Ultra $^{\text {ma }}$ RNA Library Prep Kit (NEB, USA) following the manufacture's recommendations. Briefly, poly (A) mRNA was purified from total RNA using oligo (dT)-attached magnetic beads and then broken into short fragments to synthesize double-stranded cDNA using random hexamer primer and M-MuLV reverse transcriptase (Superscript II, Life Technologies, CA, USA). The synthesized cDNA was subjected to end-repair, phosphorylation, $3^{\prime}$ adenylation, and ligation of adapters. Afterwards, cDNA libraries were generated by polymerase chain reaction (PCR), and the library preparations were sequenced on an Illumina HiSeqTM 2500 sequencing platform (commercial service) in pair-end mode with a read length of $100 \mathrm{bp}$.

To obtain clean reads, raw reads were cleaned by removing adapter sequences, low quality bases (Length threshold value $>35 \mathrm{bp}$ ), 3 ' -end low quality bases (Quality threshold value $>20$ ) and the reads containing ploy-N. The quality of raw data was evaluated using FastQC software (http://www.bioinformatics.babraham.ac.uk/projects/ fastqc/), and low quality reads were discarded by using NGS QC Toolkit v2.3.3 software (http://www.nipgr.ac.in/ ngsqctoolkit.html). Clean reads were assembled into contigs using Trinity software (version: trinityrnaseq_r20131110) with min_kmer_cov set to 2 and all other parameters set to default [23]. The generated contigs were clustered into transcripts by using TGICL software system [24]. The longest one of each transcript set was defined as a unigene for further functional annotation.

\section{Functional annotation and protein-coding sequence prediction}

All unigenes were searched against public databases, including NCBI Nr (non-redundant protein; E-value $<1 \mathrm{E}-5$ ), SwissProt (http://www.ebi.ac.uk/uniprot/; E-value <1E-5),
KOG (euKaryotic Ortholog Group; http://www.ncbi.nlm. nih.gov/COG/; E-value <1E-3), GO (Gene Ontology; http://www.geneontology.org/; E-value <1E-6) and KEGG (Kyoto Encyclopedia of Genes and Genomes; http://www. genome.jp/kegg/; E-value <1E-10) databases. Genes encoding protein domains were identified by searching against Pfam (Protein Family; http://pfam.xfam.org/; E-value < 0.01) database. GO classification was conducted using Blast2GO v2.5 [25] with an E-value of 1E-6, and KEGG classification was performed using KASS (vr140224) [26] and the KEGG Automatic Annotation Server.

In specific cases, putative functions of S. crosnieri protein were further investigated by examining multiple-sequence alignments for conserved functional domains and/or by performing phylogenetic analyses. In those instances, searches against the NCBI Nr database using BLAST were conducted to obtain homologous sequences. Alignment of amino acid sequences was performed using MUSCLE v3.8.31 [27]. The phylogenetic tree was conducted on the basis of amino acid sequence alignment using the maximum likelihood method as implemented in PhyML v3.0 [28]. The node reliability was calculated from 100 bootstrap replications. In addition, functional domain analysis was performed with SMART (http:// smart.embl.de/).

\section{Identification of genes under positive selection}

Detection of genes that have undergone positive selection can provide insights into the process of adaptive evolution [29]. In the present study, we performed a maximum likelihood approach to detect signals of positive selection in S. crosnieri inhabiting both hydrothermal vents and cold seeps. We followed the method of comparative transcriptomic analyses to identify one-to-one orthologs. Blast-based approach was performed to extract the coding sequences (CDS) of each putative unigene according to the BLASTX results. For sequences that did not have alignment results, the software ESTScan [30] was used to determine their directions. The amino acid sequences were acquired by translating the CDS using the standard codon table. Reciprocal BLASTP was conducted for all amino acid sequences with a cut-off E-value of $1 \mathrm{E}-5$. OrthoMCL v2.0.3 [31] was employed to construct orthologous groups using a Markov Cluster algorithm with default settings. Amino acid sequence alignment and phylogenetic tree construction were both followed the methods mentioned above.

The ratio $(\omega)$ of the non-synonymous $\left(\mathrm{d}_{\mathrm{N}}\right)$ nucleotide substitution rate to the synonymous $\left(\mathrm{d}_{\mathrm{S}}\right)$ nucleotide substitution rate can be used as an indicator of selective pressure operating on a protein-coding gene. The ratio $\omega>1$ indicates positive selection, $\omega=1$ suggests neutral selection, and $\omega<1$ represents negative selection [32]. We employed the site model that allowed $\omega$ to vary among sites to assess positive selection episodes affecting specific amino acid sites as 
implemented in the CODEML program in the PAML 4 package [33]. Likelihood ratio tests (LRTs) were conducted to calculate log-likelihood values between a neutral model that provided two codon site categories with $\omega<1$ and $\omega=1$ respectively and an alternative model that provided another category for sites with $\omega>1$, which indicated positive selection. Two times the difference between the log-likelihood values for the two models were used to perform chi-square test with two degrees of freedom. The $P$ values were computed based on the chi-square statistic and further adjusted by the False Discovery Rate (FDR) method. Afterwards, the Bayes Empirical Bayes (BEB) method was applied to calculate the posterior probability (PP) for site classes to identify sites under positive selection [34]. Codon sites with the PP value $>0.95$ were treated as positively selected sites. Genes with adjusted $P$ values $<0.05$ and with positively selected sites were termed as positively selected genes (PSGs) in the following analysis.

\section{Quantification and functional analysis of differentially expressed genes}

Gene expression levels in each sample were estimated by mapping clean reads to the assembled transcriptome to obtain read counts for each gene using RSEM [35]. The abundance of all genes was normalized and calculated using uniquely mapped reads by the expected number of Fragment Per Kilobase of transcript sequence per Millions (FPKM) base pairs sequenced method, which takes into account the influence of both sequencing depth and gene length on read count [36]. Differential expression analysis was implemented using the DESeq $R$ package v1.12.0 based on the negative binomial distribution [37]. The DESeq normalization method was applied to normalize read counts as it is widely studied and generally performs well relative to other methods [38]. After normalization, differential expression hypothesis testing was performed on the data. $P$ values were corrected for multiple testing using the Benjamini-Hochberg's method [39]. In this study, the adjusted $P$ value (Padj) $<0.05$ and the absolute value of the $\log 2$ (fold change) $>1$ were used as the thresholds to select differentially expressed genes (DEGs) between the vent and seep datasets.

Functional enrichment analyses including $\mathrm{GO}$ and KEGG pathway were performed to investigate which GO items and metabolic pathways the DEGs participated in, respectively. Specifically, GO enrichment analysis of candidate genes was implemented in the GOseq $\mathrm{R}$ package [40], which can eliminate gene length bias. To circumvent the problem of multi-testing, the FDR approach was applied to correct significant levels [41]. GO terms with an FDR threshold of 0.05 were considered significantly enriched by DEGs. For KEGG enrichment analysis, candidate gene lists were incorporated to the KEGG database to identify genes involved in particular biological processes and pathways that occur at a higher frequency than would be expected for a randomly selected set of genes. Here, we used KOBAS software v2.0.12 [42] to test the statistical enrichment of candidate genes in KEGG pathways. The pathways with FDR less than 0.05 were defined to be statistically represented. In addition, the DEG datasets were hierarchically clustered and visualized by using Pheatmap v1.0.8 of R package [43] to estimate expression patterns of DEGs between $\mathrm{HV}$ and CS.

\section{Quantitative real-time PCR (qRT-PCR) verification}

To validate the expression level of the DEGs obtained by RNA-Seq, qRT-PCR was conducted with the RNA used for transcriptome sequencing. The first-strand cDNA was synthesized by using M-MLV reverse transcriptase (Promega, Madison, USA) and oligodT. The SYBR Green RT PCR assay was performed in an ABI PRISM 7300 Sequence Detection System (Applied Biosystems). Ten pairs of gene-specific primers (Additional file 1: Table S1) were used to amplify the partial cDNA sequences, respectively. All experiments were conducted three times. The relative expression level of the target genes was calculated using the $2^{-\Delta \Delta C t}$ method with the $\beta$-actin gene as internal control. The results were subjected to one-way analysis of variance (ANOVA) using SPSS 17.0 software (SPSS Inc., Chicago, IL, USA), and the cut-off $P$ value of 0.05 was considered statistically significant.

\section{Results}

De novo assembly and functional annotation of $S$. crosnieri transcriptomes

A total of 430,940,036 raw reads were generated from $S$. crosnieri transcriptomes, of which 222,129,956 raw reads from vent samples and 208,810,080 raw reads from seep samples. All raw-sequence reads data have been deposited in the NCBI Sequence Read Archive (SRA) database under the accession number SRP151635. After filtering, 20.17G and 19.62G clean bases were obtained for the vent and seep samples, respectively. Over $98 \%$ clean Illumina reads in all samples exceeded Q20, indicating high quality of the sequencing data. Then clean reads were assembled into 189,543 transcripts with an average length of $583 \mathrm{bp}$ and N50 value of $796 \mathrm{bp}$, and 108,237 unigenes with an average length of $838 \mathrm{bp}$ and N50 value of $1125 \mathrm{bp}$. The statistics for the data output and de novo assemblies are summarized in Table 1.

A total of 39,806 (36.78\%) unigenes had at least one significant hit in the Nr, SwissProt, KOG, GO, or KEGG database (Table 1). Based on $\mathrm{Nr}$ annotations, we used the GO classification system to functionally categorize unigenes. In total, 30,486 (28.17\%) unigenes were successful annotated by $\mathrm{GO}$ analysis and were assigned to three major GO categories: biological process (138,448, 45.86\%), cellular component $(121,617,40.29 \%)$ and molecular function $(41,819,13.85 \%)$ (Additional file 2: Figure S1A). These 
Table 1 Summary of assembling and functional annotation of S. crosnieri transcriptomes

\begin{tabular}{|c|c|c|c|}
\hline & Hydrothermal vent & Cold seep & Total \\
\hline \multicolumn{4}{|l|}{ Sequencing data statistics } \\
\hline Raw reads & $222,129,956$ & $208,810,080$ & $430,940,036$ \\
\hline Clean bases (Gb) & 20.17 & 19.62 & 39.79 \\
\hline Clean reads & $161,376,548$ & $157,076,052$ & $318,452,600$ \\
\hline \multicolumn{4}{|l|}{ Assembly statistics } \\
\hline Number of transcripts & 189,543 & & \\
\hline Mean length of transcripts & 583 & & \\
\hline N50 of transcripts & 796 & & \\
\hline Number of unigenes & 108,237 & & \\
\hline Mean length of unigenes & 838 & & \\
\hline N50 of unigenes & 1125 & & \\
\hline \multicolumn{4}{|l|}{ Functional annotation } \\
\hline NCBI non-redundant (nr) database & $36,114(33.37 \%)$ & & \\
\hline SwissProt & $32,419(29.95 \%)$ & & \\
\hline KOG & $28,605(26.43 \%)$ & & \\
\hline KEGG & $13,588(12.55 \%)$ & & \\
\hline GO & $30,486(28.17 \%)$ & & \\
\hline Annotated in all database & $11,140(10.29 \%)$ & & \\
\hline Annotated in at least one database & $39,806(36.78 \%)$ & & \\
\hline
\end{tabular}

GO terms were further subdivided into 64 subcategories. In KOG analysis, the main function classifications were found to be 'General function prediction only', 'Signal transduction mechanisms, 'Posttranslational modification, protein turnover, chaperones' and 'Translation, ribosomal structure and biogenesis' (Additional file 2: Figure S1B). In addition, 13,588 unigenes were mapped to 350 KEGG pathways, with 'Signal transduction' being the most abundant category followed by 'Carbohydrate metabolism' and 'Translation' (Additional file 2: Figure S1C). These annotation and classification will aid understanding of the gene function in S. crosnieri.

\section{PCGs between HV and CS}

A total of 5347 orthologous unigene pairs were identified in S. crosnieri between HV and CS and the phylogenic tree was constructed with the other two arthropods Daphnia pulex and Drosophilla virilis (Additional file 3: Figure S2). Of these orthologous genes, 82 were identified as PCGs with adjusted $P$ values smaller than 0.05 and with the BEB posterior probability of sites larger than 0.95 (Additional file 4: Table S2). Further analysis indicated that the PCGs between HV and CS included thioredoxin (Trx), glutathione S-transferase (GST), and rhodanese involved in antioxidation and detoxification; C-type lectin (CTL), antimicrobial peptide (AMP), heparan sulfate proteoglycans (HSPG) contributing to immune defense; DNA repair protein, splicing factor, transcription factor, transcriptional adapter $2 \mathrm{~B}$, p53 protein, ATP-dependent DNA helicase, zinc finger protein participating in genetic information processing (Table 2). The very abundant PCGs related to various functions between $\mathrm{HV}$ and CS are indicative of a strong selective force that $S$. crosnieri might undergo during the adaptation process to different deep-sea chemosynthetic environments.

\section{DEGs between HV and CS}

A consistent expression tendency between the results based on qRT-PCR and RNA-Seq data (Additional file 1: Table S1) was detected, showing the accuracy of the RNA-Seq. A total of 545 unigenes were differentially expressed between vent and seep S. crosnieri samples. Among them, 339 (62.2\%) genes showed higher expression levels in HV than in CS and 206 (37.8\%) genes showed lower expression levels in HV than in CS (Additional file 5: Table S3). The relation between the FDR and FC (fold change) for all DEGs is shown in the volcano plots (Fig. 1). The expression heatmap showed remarkably different expression patterns of 545 DEGs (Fig. 2) with detailed information in Additional file 6: Figure S3, which revealed the differences between the adaptation to hydrothermal vents and cold seeps in S. crosnieri. Of the 545 DEGs, 193 were annotated to 439 GO terms accompanied by 145 and 48 genes with relatively high expression in HV and CS, respectively. In comparison with CS, more up-regulated subcategories were significantly enriched in $\mathrm{HV}$ (Fig. 3a, 
Table 2 PSGs related to stress response, immunity and genetic information processing between vent and seep S. crosnieri

\begin{tabular}{|c|c|c|c|}
\hline Gene category & Gene description & $P$-value & Adjusted $P$-value \\
\hline \multicolumn{4}{|c|}{ Stress response and immunity } \\
\hline $\operatorname{Tr} x$ & Thioredoxin domain-containing protein 11 & $3.23 \mathrm{E}-14$ & 4.01E-12 \\
\hline GST & Glutathione S-transferase 11 & $5.51 \mathrm{E}-10$ & $5.03 \mathrm{E}-08$ \\
\hline RHOD & Rhodanese 1-like protein & $8.75 \mathrm{E}-04$ & $2.66 \mathrm{E}-02$ \\
\hline$C T L$ & C-type lectin 2 & 1.39E-04 & $5.14 \mathrm{E}-03$ \\
\hline HSPG & Basement membrane-specific heparan sulfate proteoglycan core protein isoform X15 & 4.83E-07 & $2.88 \mathrm{E}-05$ \\
\hline AMP & Antimicrobial peptide type 2 precursor lib & $6.72 \mathrm{E}-05$ & $2.55 \mathrm{E}-03$ \\
\hline GILT & Gamma-interferon-inducible lysosomal thiol reductase & $6.27 \mathrm{E}-07$ & $3.54 \mathrm{E}-05$ \\
\hline \multicolumn{4}{|c|}{ Genetic information processing } \\
\hline RAD4 & DNA repair protein RAD4 & 7.98E-04 & $2.45 \mathrm{E}-02$ \\
\hline SRSF & Serine/arginine-rich splicing factor & $1.70 \mathrm{E}-07$ & $1.12 \mathrm{E}-05$ \\
\hline BTF3 & RNA polymerase II proteinral transcription factor BTF3 & $2.00 \mathrm{E}-15$ & $3.65 \mathrm{E}-13$ \\
\hline$A D A 2 B$ & Transcriptional adapter 2B & 0 & 0 \\
\hline p53 & p53 protein & $1.40 \mathrm{E}-10$ & $1.32 \mathrm{E}-08$ \\
\hline DNA2 & ATP-dependent DNA helicase 2 & $1.51 \mathrm{E}-04$ & $5.46 \mathrm{E}-03$ \\
\hline$E Z H$ & Enhancer of zeste protein & $1.19 \mathrm{E}-03$ & $3.56 \mathrm{E}-02$ \\
\hline ZNF268 & Zinc finger protein 268 & $3.18 \mathrm{E}-07$ & 2.01E-05 \\
\hline
\end{tabular}

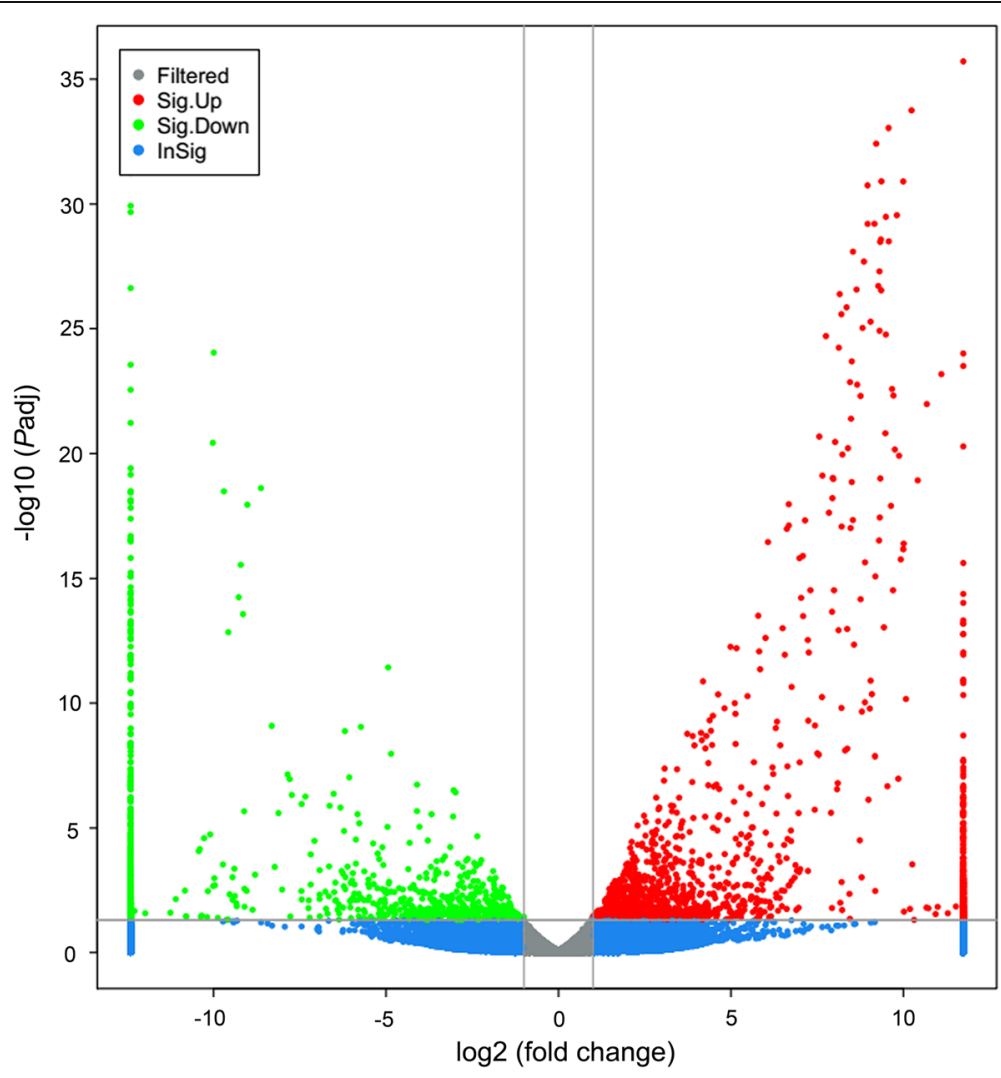

Fig. 1 Volcano plot showing DEGs between HV and CS. The red and green dots represent up-regulated and down-regulated DEGs in HV, respectively; the blue dots represent non-DEGs. $x$-axis: log2 fold change; $y$-axis: - log10 (Padj) for each DEG. vertical dotted lines: fold change $\geq 2$ or $\leq$; horizontal dotted line: the significance cut-off (Padj value $=0.05$ ) 


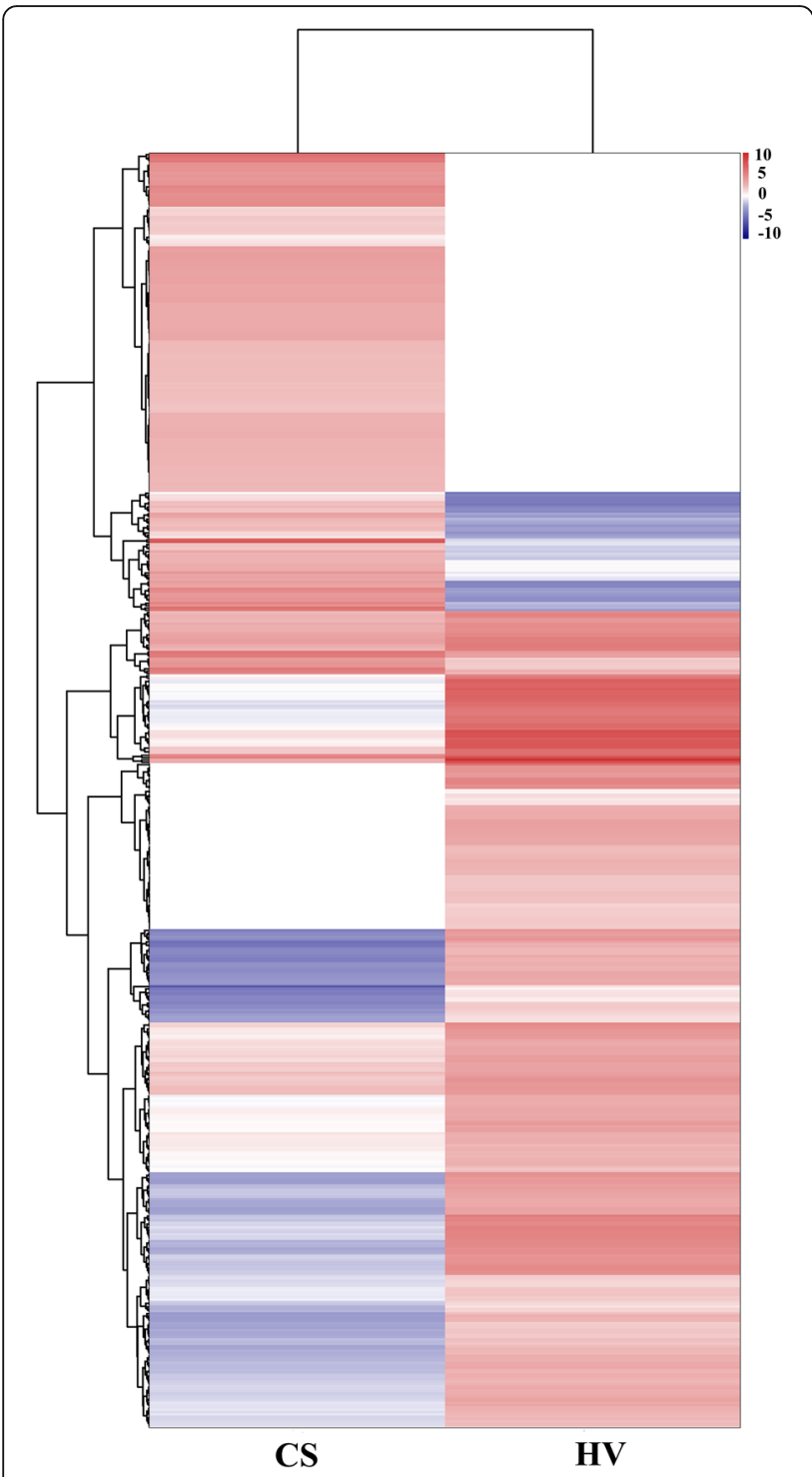

Fig. 2 Hierarchical clustering analysis for the 545 DEGs between HV and CS transcriptomes. The clustering indicates similar expression patterns among $S$. crosnieri samples ( $x$-axis) and among the genes (y-axis). The expression level is represented by color intensities (red color indicates the higher expression, and blue color indicates the lower expression of the gene)

b), among which four subcategories were potentially involved in environmental adaptation, including 'response to oxidative stress' (GO:0006979), 'response to heat' (GO:0009408), 'phagocytosis' (GO:0006909) and 'peroxidase activity' (GO:0004601). In agreement to these findings, a functional enrichment analysis on KEGG pathway showed significant enrichment of 'endocytosis' (ko04144), 'spliceosome' (ko03040) and 'metabolism of xenobiotics by cytochrome P450' (ko00980) in HV (Fig. 3c), but no significantly enriched KEGG pathways were detected in CS. These results indicated that the deep-sea squat lobsters in HV might confront more severe chemical substance threats than those in CS.
The DEGs between HV and CS were associated with diverse gene functions. Specifically, all nine unigenes relevant to antioxidation and detoxification were found to be up-regulated in HV (Table 3), including superoxide dismutase (SOD), peroxidase, dihydrodiol dehydrogenase (DDH), cystathionine gamma-lyase (CSE) and GST. In addition, five DEGs annotated as heat shock proteins (HSPs) were also found to be up-regulated in HV. The up-regulated HSPs included two members of the small HSP family (HSP21 and HSP27) and one member of the HSP70 family (Table 3). In terms of immune-related DEGs, alpha 2-macroglobulin (A2M) was found to be up-regulated in CS, while complement component $1 \mathrm{q}$ (C1q), immunoglobulin (Ig), serine protease and tissue factor pathway inhibitor (TFPI) were expressed consistently more highly in HV than in CS. Meanwhile, five unigenes annotated as CTL were identified as DEGs, of which four were up-regulated in HV. These varied categories of genes with differential expression patterns might be important for $S$. crosnieri to tolerate environmental heterogeneity between $\mathrm{HV}$ and CS.

\section{Discussion}

As the typical deep-sea chemosynthetically-driven ecosystems, hydrothermal vents and cold seeps have been reported to differ in many aspects, including geological settings, temperature gradient and chemicals used for energy [3]. Despite their habitat differences, these two types of chemosynthetic ecosystems support dense populations of the same species such as decapod crustaceans. To gather fundamental knowledge about deep-sea adaptation of these specialized macro-benthos to different chemosynthetic environments, we investigated transcriptome profiles of the dominant species, S. crosnieri inhabiting both deep-sea vents and seeps. We provided further evolutionary context to our analysis by identifying genes that underwent positive selection. As expected, our analyses identified a number of plausible contributors to the survival of $S$. crosnieri in both deep-sea vents and cold seeps, including genes that act in stress response, immunity defense and genetic information processing. However, these candidates involved in genetic adaptation to different deep-sea chemosynthetic environments in S. crosnieri should be verified in the future.

\section{Signals of positive selection in S. crosnieri during adaptation into deep-sea vents and seeps}

Transcriptome-wide analysis of the rates of non-synonymous to synonymous nucleotide substitutions represents a promising approach to quantitatively measure the selection force by identifying genes under positive selection $[44,45]$. The heterogeneous environmental conditions between hydrothermal vents and cold seeps can be an important selective force driving adaptive divergence of macro-organisms 


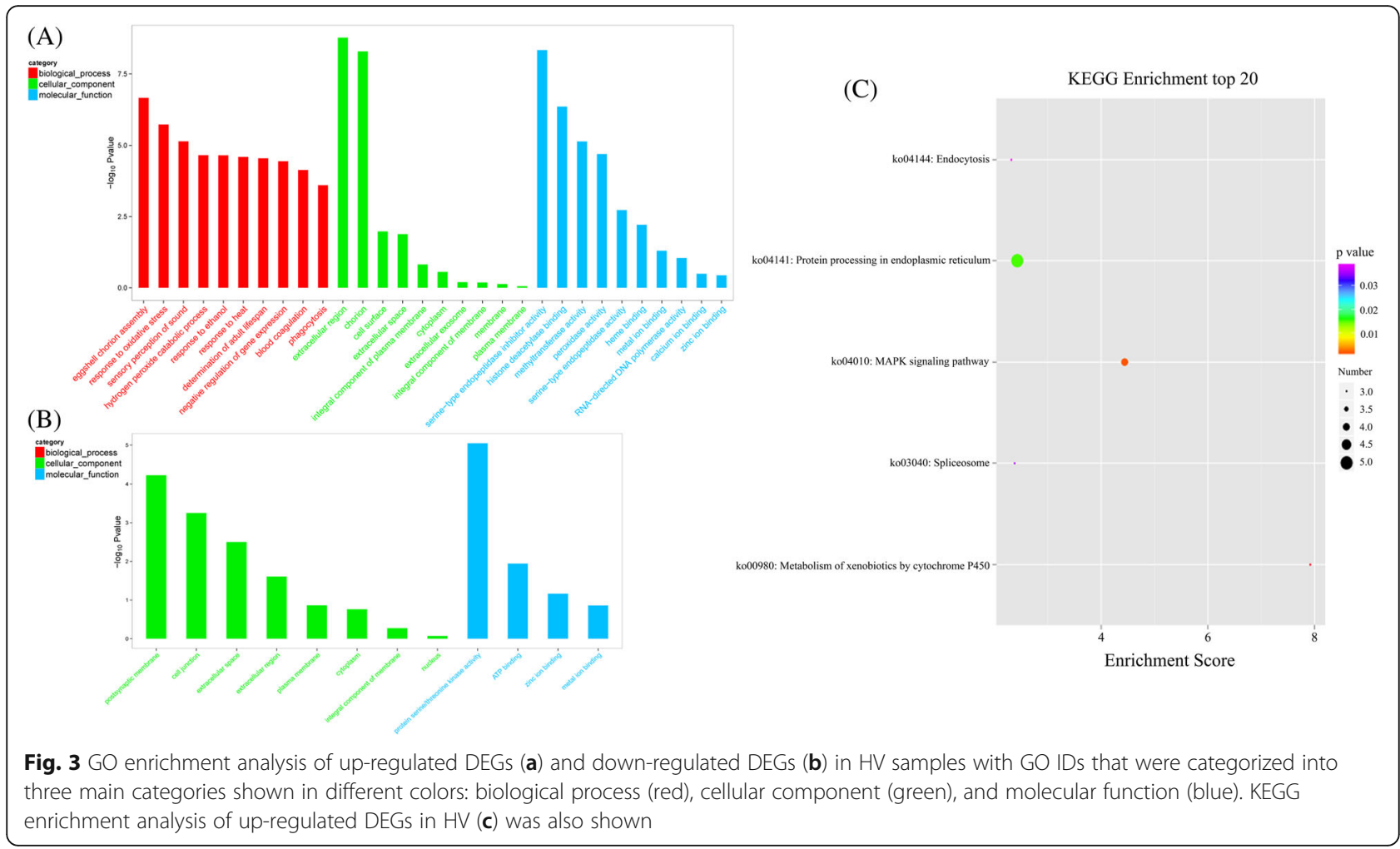

living in both habitats. In this study, we used the maximum likelihood approach to trace signals of positive selection in S. crosnieri during adaptation into deep-sea vents and seeps and detect positively selected sites of functional genes (Additional file 7: Figure S4). A total of 82 genes were identified to be positively selected and involved in many biological processes, including antioxidation, detoxification, immunity and genetic information processing.

Genes that related to stress response have been reported to evolve under positive selection in diverse groups of organisms, including algae [46], insects [47, 48] and mussels [10]. Representative genes involved in antioxidation and detoxification were also found to be positively selected in S. crosnieri between HV and CS. Enzymes encoded by these genes include Trxs which act as antioxidants by catalyzing the reduction of other proteins by cysteine thiol-disulfide exchange [49], rhodanese that functions to detoxify cyanide into relatively nontoxic thiocyanate [50], and GSTs involved in the cellular detoxification of various endogenous and exogenous electrophilic compounds [51]. As in GST, four putative GST classes (mu, sigma, theta, and kappa) were identified in $S$. crosnieri transcriptomes based on phylogenetic analysis of GSTs among different arthropod species (Fig. 4a). Positively selected mutations were only detected in the gene encoding theta-class GST in S. crosnieri (ScGSTT), which have resulted in 13 amino acid substitutions (Fig. 4b). Homologous sequence comparison revealed that ScGSTT included the $\mathrm{N}$-terminal and $\mathrm{C}$-terminal domains, glutathione binding sites, as well as other conserved residues of theta-class GSTs (Fig. 4b) [52]. It is noteworthy that almost all positively selected sites are located in the vicinity of the active site of the $\mathrm{N}$-terminal domain in ScGSTT. It has been shown that the amino acid diversity at the $\mathrm{N}$ - and $\mathrm{C}$ - terminal binding domains of GST defines substrate selectivity [52, 53]. We speculate that divergent evolution of key functional domains of ScGSTT has probably contributed to different stress tolerance capabilities of $S$. crosnieri to survive in different deep-sea chemosynthetic environments. However, the specific feature and function of ScGSTT should be pursued experimentally in the future.

In addition to stress response genes, immune-related genes, such as CTLs which are responsible for the initiation of the host immune response against pathogen [54], and AMPs which are important effector protein of innate immunity [55], were also found to harbor positively selected mutations (Additional file 7: Figure S4A). Positive selection in genes related to immune response might be a consequence of adaptive evolution in S. crosnieri during adaptation into deep-sea vents and seeps when confronted with different environmental stressors, such as diverse pathogens. We also noticed that a couple of genes involved in DNA repair and translation regulation have evolved under positive selection (Additional file 7: Figure 
Table 3 Summary of DEGs involved in antioxidation and detoxification, heat shock proteins, and immune defense

\begin{tabular}{|c|c|c|c|c|c|c|}
\hline \multirow{2}{*}{$\begin{array}{l}\text { Gene } \\
\text { category }\end{array}$} & \multirow[t]{2}{*}{ Unigene ID } & \multicolumn{2}{|c|}{ Expression level } & \multirow{2}{*}{$\begin{array}{l}\log 2(\text { fold } \\
\text { change) }\end{array}$} & \multirow[t]{2}{*}{ Padj } & \multirow[t]{2}{*}{ Annotation } \\
\hline & & $\mathrm{HV}$ & CS & & & \\
\hline \multicolumn{7}{|c|}{ Antioxidation and detoxification } \\
\hline SOD & comp117154_c0_seq4 & 64.14 & 2.25 & 5.16 & $\begin{array}{l}4.11 \mathrm{E}- \\
10\end{array}$ & Superoxide dismutase, Cu-Zn family [Procambarus clarkil] \\
\hline \multirow[t]{4}{*}{ Peroxidase } & comp78515_c1_seq1 & 42.17 & 0.21 & 8.21 & $\begin{array}{l}8.24 \mathrm{E}- \\
08\end{array}$ & Peroxidase, putative [/xodes scapularis] \\
\hline & comp78515_c0_seq1 & 42.77 & 0.03 & 11.10 & $\begin{array}{l}1.63 \mathrm{E}- \\
20\end{array}$ & Peroxidase-like protein isoform X2 [Linepithema humile] \\
\hline & comp120735_c0_seq1 & 32.10 & 1.94 & 4.16 & $\begin{array}{l}1.44 \mathrm{E}- \\
06\end{array}$ & peroxidase-like [Plutella xylostella] \\
\hline & comp117925_c0_seq1 & 320.26 & 1.31 & 8.10 & $\begin{array}{l}5.87 \mathrm{E}- \\
05\end{array}$ & Thyroid peroxidase-like [Zootermopsis nevadensis] \\
\hline CSE & comp120565_c0_seq2 & 24.08 & 0.10 & 7.97 & $\begin{array}{l}1.65 \mathrm{E}- \\
16\end{array}$ & Cystathionine gamma-lyase-like [Limulus polyphemus] \\
\hline$D D H$ & comp117984_c0_seq2 & 114.80 & 26.70 & 2.56 & $\begin{array}{l}1.57 \mathrm{E}- \\
02\end{array}$ & $\begin{array}{l}\text { trans-1,2-dihydrobenzene-1,2-diol dehydrogenase-like [Fopius } \\
\text { arisanus] }\end{array}$ \\
\hline \multirow[t]{2}{*}{ GST } & comp60860_c0_seq1 & 164.94 & 41.94 & 2.13 & $\begin{array}{l}2.11 \mathrm{E}- \\
02\end{array}$ & Glutathione S-transferases [Macrobrachium nipponense] \\
\hline & comp115940_c0_seq2 & 1345.57 & 10.67 & 7.24 & $\begin{array}{l}2.57 \mathrm{E}- \\
07\end{array}$ & Glutathione S-transferase s4 [Lissorhoptrus oryzophilus] \\
\hline
\end{tabular}

Heat shock proteins

HSP

$$
\begin{aligned}
& \text { comp122999_c1_seq6 } \\
& \text { comp123864_c1_seq1 } \\
& \text { comp120701_c2_seq3 } \\
& \text { comp116171_c0_seq1 } \\
& \text { comp108920_c0_seq1 } \\
& \text { comp76811_c0_seq1 } \\
& \text { comp108897_c0_seq1 }
\end{aligned}
$$

Immune defense

$C T L$

$\begin{array}{llll}\text { comp124003_c1_seq3 } & 2124.07 & 5.61 & 8.96 \\ \text { comp123320_c0_seq1 } & 201.02 & 0.90 & 8.20 \\ \text { comp123413_c2_seq2 } & 2242.87 & 27.81 & 6.68 \\ \text { comp107558_c1_seq2 } & 74.66 & 0.15 & 9.75 \\ \text { comp107560_c0_seq1 } & \mathbf{0 . 0 9} & \mathbf{9 4 . 8 3} & \mathbf{-}\end{array}$

C19$$
\text { comp }
$$

comp117788_coseq

TFPI
3.39

3.39E02

$5.42 \mathrm{E}-$ 04

4.46E- Heat shock protein 21 [Macrobrachium rosenbergi] 02

4.64E- Heat shock protein 21 [Macrobrachium rosenbergii] 02

9.56E- Heat shock protein 27, partial [Procambarus clarki] 03

9.86E- Heat shock protein 70 [Portunus trituberculatus]

07

1.97E- Heat shock protein $70 \mathrm{kDa}$ [Xantho incisus]

02

4.37E- C-type lectin [Panulirus homarus]

26

9.66E- C-type lectin [Panulirus homarus]

23

9.16E- C-type lectin [Panulirus homarus]

15

1.23E- putative c-type lectin [Procambarus clarki]

17

\section{8 nipponense]}

9.21E- putative complement component 1, q subcomponent protein 29 [Procambarus clarkii] 13

$2.48 \mathrm{E}-$ 24

comp122322_c0_seq1 $665.65 \quad 1.61 \quad 9.03$
$7.82 \mathrm{E}-$

putative complement component 1, q subcomponent protein [Procambarus clarkii]

tissue factor pathway inhibitor 2-like [Cyprinus carpio]

8.62E- tissue factor pathway inhibitor isoform X4 [Struthio camelus australis] 
Table 3 Summary of DEGs involved in antioxidation and detoxification, heat shock proteins, and immune defense (Continued)

\begin{tabular}{|c|c|c|c|c|c|c|}
\hline \multirow{2}{*}{$\begin{array}{l}\text { Gene } \\
\text { category }\end{array}$} & \multirow[t]{2}{*}{ Unigene ID } & \multicolumn{2}{|c|}{ Expression level } & \multirow{2}{*}{$\begin{array}{l}\log 2 \text { (fold } \\
\text { change) }\end{array}$} & \multirow[t]{2}{*}{ Padj } & \multirow[t]{2}{*}{ Annotation } \\
\hline & & $\mathrm{HV}$ & CS & & & \\
\hline & & & & & 08 & \\
\hline & comp123942_c0_seq1 & 871.37 & 2.52 & 8.82 & $\begin{array}{l}3.18 \mathrm{E}- \\
22\end{array}$ & Tissue factor pathway inhibitor [Limulus polyphemus] \\
\hline & comp117589_c0_seq1 & 222.59 & 0.75 & 8.64 & $\begin{array}{l}1.16 \mathrm{E}- \\
23\end{array}$ & Tissue factor pathway inhibitor [Ophiophagus hannah] \\
\hline \multirow[t]{4}{*}{$\begin{array}{l}\text { Serine } \\
\text { protease }\end{array}$} & comp121531_c0_seq1 & 382.44 & 0.94 & 9.16 & $\begin{array}{l}4.37 E- \\
26\end{array}$ & Serine proteinase-like protein [Macrobrachium nipponense] \\
\hline & comp122830_c0_seq1 & 10.24 & 0.07 & 7.44 & $\begin{array}{l}3.97 \mathrm{E}- \\
07\end{array}$ & Serine protease 38 precursor [Nasonia vitripennis] \\
\hline & comp118617_c0_seq1 & 44.91 & 0.20 & 7.96 & $\begin{array}{l}9.48 \mathrm{E}- \\
20\end{array}$ & Serine proteinase stubble-like [Tropilaelaps mercedesae] \\
\hline & comp115439_c0_seq1 & 8613.91 & 4331.84 & 7.09 & $\begin{array}{l}2.52 \mathrm{E}- \\
11\end{array}$ & putative trypsin serine protease [Procambarus clarki] \\
\hline $\lg$ & comp118268_c0_seq1 & 47.40 & 8.50 & 2.74 & $\begin{array}{l}2.63 \mathrm{E}- \\
02\end{array}$ & Immunoglobulin [Oryctes borbonicus] \\
\hline \multirow[t]{2}{*}{$A 2 M$} & comp101450_c1_seq1 & 0.00 & 14.07 & $-\operatorname{lnf}$ & $\begin{array}{l}1.77 \mathrm{E}- \\
02\end{array}$ & Alpha 2-macroglobulin, partial [ Scylla paramamosain] \\
\hline & comp120130_c2_seq1 & 0.00 & 6.95 & $-\operatorname{lnf}$ & $\begin{array}{l}8.69 \mathrm{E}- \\
04\end{array}$ & Alpha-2-macroglobulin [ Pacifastacus leniusculus] \\
\hline
\end{tabular}

DEGs highlighted in bold are up-regulated in CS

S4B). For example, RAD4, known as a repair factor, plays a key role in the detection of DNA damage and initiation of DNA repair [56]. The serine/arginine-rich splicing factors participate in a wide range of alternative splicing events and can function as modulator of DNA repair [57]. The p53 protein is widely involved in numerous cellular processes, including DNA transcription, DNA repair, apoptosis as well as maintenance of genomic stability [58]. In the case of RAD4, sequence analysis showed that RAD4 protein identified from S. crosnieri transcriptomes contained a typical transglutaminase-like domain and three beta-hairpin domains (BHDs) that are responsible for DNA binding (Fig. 5). Previous biochemical and cellular studies have shown that beta-hairpin from BHD_3 plays an import role in the recognition of DNA damage $[59,60]$. Substitution analysis of RAD4 in the vent and seep squat lobster by the site model showed that BHD_3 was positively selected (Fig. 5a), indicating different environmental conditions could have affected the ability of RAD4 to recognize DNA damage. Ample evidences indicated the effect of environmental exposure to heavy metals and heat stress on the integrity of DNA and the repair system [61, 62]. Hydrothermal vents, usually characterized with high temperature, sulphide and heavy metal concentrations, seem more severe than seeps as environments for organisms [3]. Therefore, the positive selection in those key genes associated with DNA repair may imply their roles for $S$. crosnieri to prevent potential heat stress- and heavy metal-induced DNA damage in hydrothermal vents.

\section{DEGs involved in adaptation to deep-sea vents and seeps} in S. crosnieri

It has been known that environmental stresses can lead to increased cellular levels of reactive oxygen species (ROS), which can pose a threat to cells by causing oxidative damage on a wide diversity of molecules, especially proteins and lipids $[63,64]$. Aerobic organisms can adapt to the enhanced ROS production during environmental stresses by up-regulating antioxidant defenses [65]. Compared to cold seeps, hydrothermal vents seem more severe as environments for organisms [3]. Concordantly, our study showed that a number of antioxidant genes were up-regulated in $\mathrm{HV}$. Proteins encoded by these genes either contributed to directly scavenge ROS (e.g., SOD and peroxidase), or participated in protecting cells from toxic effects of ROS and repairing damaged cellular components targeted by ROS (e.g., GSTs and HSPs). Among up-regulated genes in $\mathrm{HV}$, we detected one unigene annotated as copper/zinc superoxide dismutase $(\mathrm{Cu} / \mathrm{Zn} \mathrm{SOD})$, which catalyzes the dismutation of superoxide into molecular oxygen and hydrogen peroxide $\left(\mathrm{H}_{2} \mathrm{O}_{2}\right)$, and four unigenes annotated as peroxidase, which catalyzes the reduction of $\mathrm{H}_{2} \mathrm{O}_{2}$ into water and oxygen. $\mathrm{Cu} / \mathrm{Zn} \mathrm{SOD}$ is a copper- and zinc-containing superoxide dismutase that is crucial in preventing cells from oxidative damage [66]. Moreover, $\mathrm{Cu} / \mathrm{Zn}$ SOD has also been reported to be involved in detoxification and innate immune response of crustaceans [67, 68]. Furthermore, two genes coding for proteins related to CSE and DDH were also up-regulated in HV. Recent studies 
(A)

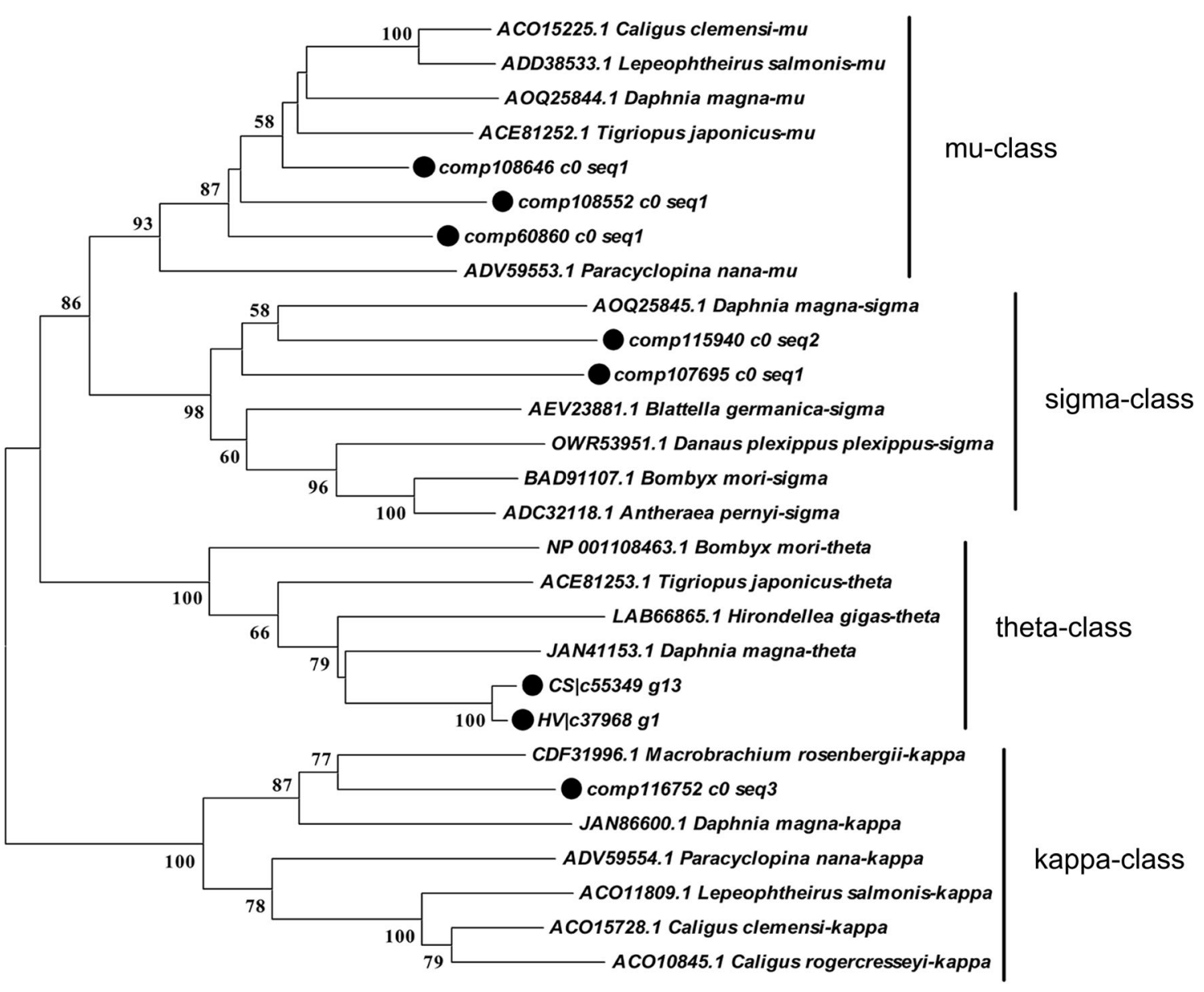

(B)

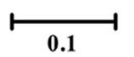

c55349_g13Shinkaia crosnieri_CS c37968_g1 Shinkaia crosnieri_HV LAB66865.1 Hirondellea gigas ACE81253.1Tigriopus japonicus JAN41153.1Daphnia magna
NP_001108463.1Bombyx mori
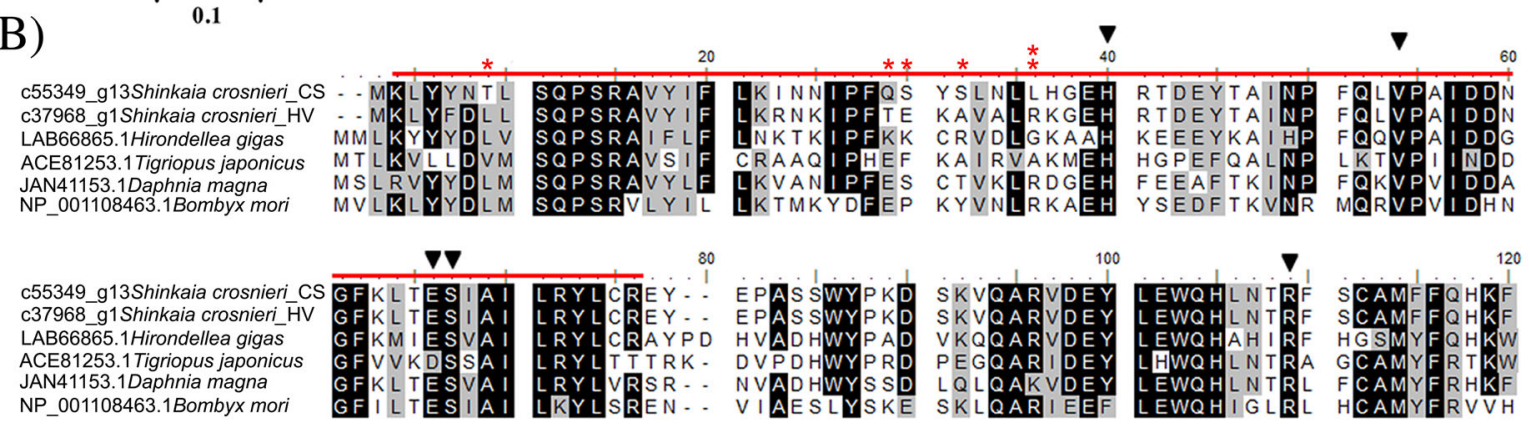
NP_001108463.1Bombyx mori

\section{0}

c55349_g13Shinkaia crosnieri_cS c37968_g1Shinkaia crosnieri_ $\mathrm{H} V$ LAB66865.1 Hirondellea gigas ACE81253.1 Tigriopus japonicus JAN41153.1Daphnia magna NP_001108463.1Bombyx mori
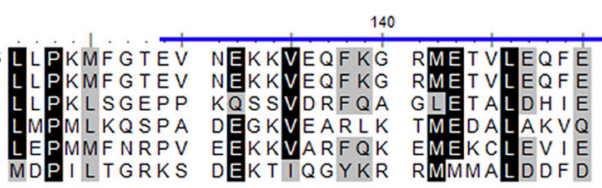

160

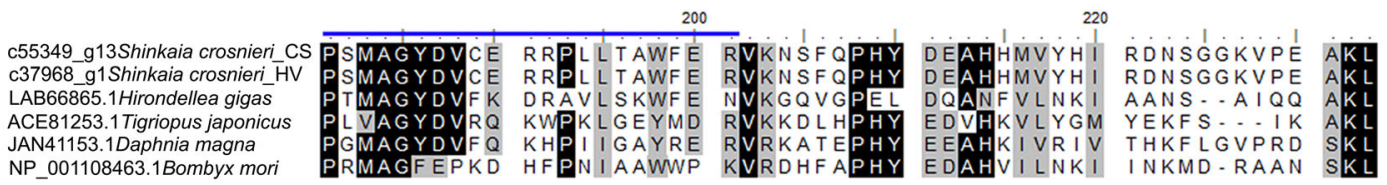

Fig. 4 (See legend on next page.) 
(See figure on previous page.)

Fig. 4 Sequence analysis of the glutathione S-transferase (GST) from S. crosnieri. a Phylogenetic analysis of amino acid sequences of GSTs from S. crosnieri (marked with circles) and those from arthropods using the maximum likelihood method. In the phylogenetic tree, each entry contains the accession number, species name and GST class. Bootstrap values (> 50\%) are indicated at branch nodes. $\mathbf{b}$ Alignment of amino acid sequences of theta-class GSTs in S. crosnieri with other four arthropods. The N-terminal domain is indicated by the red line; the C-terminal domain is indicated by the blue line; the putative GSH-binding sites (G-sites) are represented by triangles. Double asterisks stand for the amino acids in S. crosnieri with a BEB posterior probability that is larger than 0.99 , and one asterisk stands for the sites with a posterior probability higher than 0.95 but lower than 0.99

have demonstrated the antioxidative property of CSE and suggested that CSE is a critical factor in regulating the synthesis of glutathione, the first-line antioxidative defense $[69,70]$. DDH belongs to a family of aldo-keto reductases that are involved in detoxification of environmental mutagenic hazards [71]. Besides detoxification, this enzyme could be involved in regulation of intercellular ROS levels and its induction may act as a response to oxidative stress [72, 73]. Up-regulation of these gene expression might render S. crosnieri individuals in HV with a stronger antioxidant defense against ROS.

Increasing evidence has revealed that ROS can cause peroxidation of lipids, resulting in the formation of electrophilic substrates toxic to living organisms [74, 75].

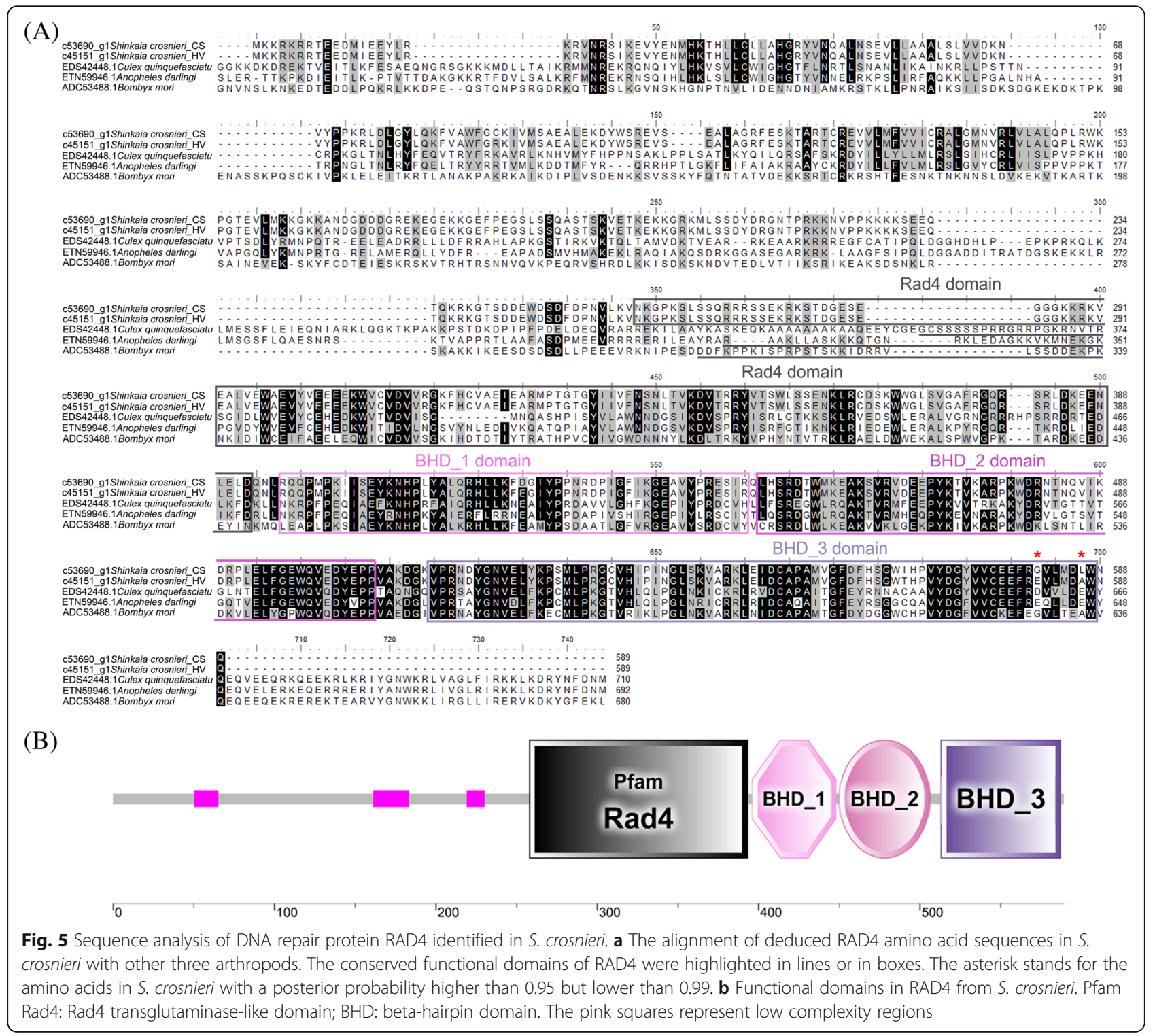


The defense mechanisms against lipid peroxidation constitute the second line of defense against oxidative stress. In this study, two unigenes encoding enzymes related to glutathione-dependent detoxification, GSTs, were found to be up-regulated in HV. Besides the protective effects against xenobiotics, GSTs also play a crucial role in protecting organisms from lipid peroxidation via detoxification of lipid peroxidation end products [75, 76]. In addition to up-regulating genes related to direct elimination of ROS or detoxification of electrophilic products during oxidation process, S. crosnieri also up-regulated gene expression of HSPs in HV against stress-activated protein misfolding and aggregation. It is well known that exposure of cells to environmental stresses can induce gene expression of HSPs that function as molecular chaperones to repair or degrade damaged proteins as cellular defenses [77]. Taken together, these results indicated that $S$. crosnieri might up-regulate a battery of genes associated with stress response to increase its capability to manage more environmental stresses in the hydrothermal vents.

Similarly, a number of immune-related genes were found to be differentially expressed, including two types of pattern recognition receptors (PRRs) that can recognize conserved molecular structures on pathogens called pathogen-associated molecular patterns (PAMPs) [78]. Of all the PRRs families, CTLs play a critical role in initiating and regulating the host immune response against pathogen exposure, which have been demonstrated to function importantly in anti-microbial immunity of many crustaceans $[54,79,80]$. Another type of differentially expressed PRRs was a C1q homolog, which contains a conserved C1q domain (Additional file 8: Figure S5). Known as a versatile PRR in innate immunity, C1q can recognize and bind to various PAMPs, and then trigger the classical complement pathway [81]. In addition to this, it is established that C1q is involved in clearance of apoptotic cells upon phagocytosis, thereby playing a major role in maintenance of immune tolerance [82, 83]. Interestingly, most differentially expressed lectin and C1q were significantly up-regulated in $\mathrm{HV}$, indicating microbial communities encountered by S. crosnieri might differ between HV and CS.

Besides PRRs, genes coding for enzymes/proteins involved in the downstream immune responses were also identified in DEGs. Among them, TFPI, serine protease and Ig were consistently up-regulated in HV. As a major regulator of blood clotting, TFPI has also been shown to possess anti-microbial properties that can execute pathogen killing [84]. Serine protease has been shown to participate in diverse defense responses in invertebrates, including synthesis of antimicrobial peptide, hemolymph coagulation and melanotic encapsulation [85]. Igs are the key components of adaptive immune system by specifically recognizing and neutralizing invading pathogens, such as bacteria and viruses [86]. Although adaptive immunity has long been considered to be an evolutionary innovation unique to vertebrates, Ig-mediated adaptive immunity has been recently reported to be involved in host defense of several crustaceans, including water fleas Daphnia [87], the white shrimp Litopenaeus vannamei [88] and the crayfsh Procambarus clarkii [89]. The gene coding for Ig in S. crosnieri harbored one Ig-like domain (Immunoglobulin C-2 Type, IGc2) (Additional file 9: Figure S6), implying its alternative adaptive immunity. However, further experiments are needed to determine the exact function of Ig in S. crosnieri. On the other side, two unigenes coding for A2M showed higher expression in CS. As a broad-spectrum proteinase, A2M functions in delivering proteinase to an endocytotic proteinase clearance pathway, thereby protecting organisms against invading pathogens [90], which has been reported in shrimp [91]. Immune gene expression differences between $\mathrm{HV}$ and CS suggested that S. crosnieri possibly performed specific immune response that generated diverse pathogen resistance to support individual adaptation when confronting different environmental stressors. Together with our finding that stress response and immune-related genes are also positively selected in S. crosnieri between HV and CS, overexpression of a battery of antioxidant and immune genes in HV suggests that oxidative stress and immune defense are more active in vent $S$. crosnieri. It might be a consequence of more environmental stresses encountered by $S$. crosnieri in hydrothermal vents than cold seeps.

\section{Conclusions}

This study represented a first step in understanding the deep-sea adaptation mechanism of the galatheid squat lobster S. crosnieri at the molecular level, and provided a comprehensive transcriptomic resource for molecular studies of this species. Through the maximum likelihood approach, we identified traces of positive selection and detected amino acid substitutions in specific proteins, which revealed that adaptation was driving the evolution of key genes associated with adaptation to deep-sea vents and seeps in S. crosnieri. In addition, a large number of DEGs were detected between HV and CS, and most of the DEGs associated with stress response and immunity were up-regulated in $\mathrm{HV}$, suggesting that hydrothermal vents might be more severe as environments for $S$. crosnieri in comparison with cold seeps. Moreover, a number of stress response and immune-related genes were found positively selected and/or differentially expressed, highlighting the importance of those key genes in adaptation of S. crosnieri to deep-sea vents and seeps. Overall, our results indicated that the capacity of $S$. crosnieri to thrive in different deep-sea chemosynthetic environments derived partly from adaptive evolution of functional genes associated with stress response and immunity, and alterations in their 
gene expression that lead to different stress resistance. Since transcriptomic analysis has limitations to capture signals of positive selection occurring in the regulatory regions, and mRNA levels are not necessarily correlated with protein abundance or activity due to post-translation modifications, further studies including systematic genomic and proteomic analyses are required to validate the results and test the proposed hypotheses.

\section{Additional files}

Additional file 1: Table S1. Gene expression analyzed by qRT-PCR and RNA-Seq. (XLSX $11 \mathrm{~kb})$

Additional file 2: Figure S1. GO classification (A), KOG function classification (B), and KEGG pathway classification (C) of all unigenes in the transcriptome of Shinkaia crosnieri. (PDF $16847 \mathrm{~kb}$ )

Additional file 3: Figure S2. Phylogenetic tree of three arthropods based on the orthologous genes. (PDF $44 \mathrm{~kb}$ )

Additional file 4: Table S2. The list of positively selected genes between vent and seep Shinkaia crosnieri. (XLSX $24 \mathrm{~kb}$ )

Additional file 5: Table S3. Differential expressed unigenes between vent and seep Shinkaia crosnieri. (XLSX 59 kb)

Additional file 6: Figure S3. Heatmap of all DEGs. (PDF $14963 \mathrm{~kb}$ ) Additional file 7: Figure S4. Partial alignment of positively selected genes. (A) Positively selected genes related to stress response and immunity. (B) Positively selected genes related to genetic information progressing. (PDF $141 \mathrm{~kb}$ )

Additional file 8: Figure S5. Deduced amino acid sequence alignment of comp123155_c0_seq2, comp117788_c0_seq1 with complement component $1 \mathrm{q}$ (C1q) from Procambarus clarkia (ASC55672), Lingula anatine (XP 013406649), and Crassostrea virginica (XP 022323368). Conserved amino acid residues were in colors. The highly conserved C19 domain was highlighted in a black box. (PDF $228 \mathrm{~kb}$ )

Additional file 9: Figure S6. Deduced amino acid sequence of immunoglobulin (Ig) in Shinkaia crosnieri. The Ig-like domain (Immunoglobulin C-2 Type, IGC2) was highlighted in a black box. The internal repeats were underlined. (PDF $276 \mathrm{~kb}$ )

\section{Abbreviations}

A2M: Alpha 2-macroglobulin; AMP: Antimicrobial peptide; ANOVA: One-way analysis of variance; BEB: Bayes Empirical Bayes; C1q: Complement component 1 q; CDS: Coding sequences; CS: A cold seep in the South China Sea; CSE: Cystathionine gamma-lyase; CTL: C-type lectin; Cu/Zn SOD: Copper/ zinc superoxide dismutase; DDH: Dihydrodiol dehydrogenase;

DEG: Differentially expressed gene; $d_{N}$ : Nonsynonymous nucleotide substitutions per site; $d_{s}$ : Synonymous nucleotide substitutions per site; FDR: False discovery rate; FPKM: Fragments per kilobase of exon model per million mapped reads; GO: Gene Ontology; GST: Glutathione S-transferase; $\mathrm{H}_{2} \mathrm{O}_{2}$ : Hydrogen peroxide; HSP: Heat shock protein; HSPG: Heparan sulfate proteoglycans; HV: The Iheya North hydrothermal vent; Ig: Immunoglobulin; IGc2: Immunoglobulin C-2 Type; KEGG: Kyoto Encyclopedia of Genes and Genomes; KOG: euKaryotic Ortholog Group; LRT: Likelihood ratio test; Nr: Non-redundant protein database; PAMP: Pathogen-associated molecular pattern; Pfam: Protein Family; PP: Posterior probability; PRR: Pattern recognition receptor; PSG: Positively selected gene; qRT-PCR: Quantitative real-time PCR; ROS: Reactive oxygen species; ROV: Remotely operated vehicle; SOD: Superoxide dismutase; SRA: Sequence Read Archive; TFPI: Tissue factor pathway inhibitor; Trx: Thioredoxin

\section{Acknowledgments}

The samples were collected by RV KEXUE. We would like to express our sincere thanks to the crews of the vessels of "KEXUE" for their help in sample collection, and to the two anonymous reviewers for their constructive comments on earlier versions of the manuscript.

\section{Funding}

This work was supported by the grants from the National Key R\&D Program of China (2018YFC0310702, 2018YFC0310802), the Senior User Project of RV KEXUE (KEXUE2018G21), National Natural Science Foundation of China

(31872215), and the "Key Research Program of Frontier Sciences" of Chinese Academy of Sciences (QYZDB-SSW-DQC036). The funding bodies had no role in the design of the study and collection, analysis, and interpretation of data and in writing the manuscript.

\section{Availability of data and materials}

The datasets supporting the results of this article are included in the article and its additional files. All sequence reads have been deposited in the NCB Sequence Read Archive (SRA) database (https://www.ncbi.nlm.nih.gov/sra) and are accessible through SRA accession number SRP151635.

\section{Authors' contributions}

$\mathrm{ZS}, \mathrm{JC}$ and $\mathrm{MH}$ conceived and designed the project. ZS collected samples. JC performed lab work, analyzed data and drafted the manuscript. MH and ZS revised the manuscript. All authors have read and approved the final version of the manuscript.

\section{Ethics approval and consent to participate}

The cruise and field study were approved by Chinese Academy of Sciences. All experimental protocols involving animals were conducted according to the guidelines of the Institutional Animal Care and Use Committee (IACUC) of the Chinese Academy of Sciences (No. 2011-2). The research was approved by the Committee on the Ethics of Animal Experiments of the Institute of Oceanology in the Chinese Academy of Sciences.

\section{Consent for publication}

Not applicable.

\section{Competing interests}

The authors declare that they have no competing interests.

\section{Publisher's Note}

Springer Nature remains neutral with regard to jurisdictional claims in published maps and institutional affiliations.

\section{Author details}

'Laboratory of Marine Organism Taxonomy and Phylogeny, Institute of Oceanology, Chinese Academy of Sciences, Qingdao 266071, China. ${ }^{2}$ Laboratory for Marine Biology and Biotechnology, Qingdao National Laboratory for Marine Science and Technology, Qingdao 266237, China. ${ }^{3}$ Center for Ocean Mega-Science, Chinese Academy of Sciences, Qingdao 266071, China. ${ }^{4}$ University of Chinese Academy of Sciences, Beijing 100049, China.

Received: 6 August 2018 Accepted: 30 April 2019

Published online: 18 May 2019

\section{References}

1. Van Dover CL, German CR, Speer KG, Parson LM, Vrijenhoek RC. Evolution and biogeography of deep-sea vent and seep invertebrates. Science. 2002;295:1253-7.

2. Desbruyères $D$, Almeida $A$, Biscoito $M$, Comtet $T$, Khripounoff $A$, Le Bris $N$, et al. A review of the distribution of hydrothermal vent communities along the northern mid-Atlantic ridge: dispersal vs. environmental controls. Hydrobiologia. 2000;440:201-16.

3. Miyazaki Jl, Beppu S, Kajio S, Dobashi A, Kawato M, Fujiwara Y, et al. Dispersal ability and environmental adaptability of deep-sea mussels Bathymodiolus (Mytilidae: Bathymodiolinae). Open J Mar Sci. 2013;3:31-9.

4. Bergquist DC, Williams FM, Fisher CR. Longevity record for a deep-sea invertebrate. Nature. 2000:403:499-500.

5. Corliss JB, Dymond J, Gordon LI, Edmond JM, von Herzen RP, Ballard RD, et al. Submarine thermal springs on the Galapagos rift. Science. 1979;203:1073-83.

6. Nies DH. Microbial heavy-metal resistance. Appl Microbiol Biotechnol. 1999; 51:730-50.

7. Levin LA. Deep-ocean life where oxygen is scarce. Am Sci. 2002:90:436-44.

8. Watanabe H, Fujikura K, Kojima S, Miyazaki Jl, Fujiwara Y. Japan: vents and seeps in close proximity. In: Kiel S, editor. The vent and seep biota. Netherlands: Springer; 2010. p. 379-401. 
9. Bettencourt R, Pinheiro M, Egas C, Gomes P, Afonso M, Shank T, et al. High-throughput sequencing and analysis of the gill tissue transcriptome from the deep-sea hydrothermal vent mussel Bathymodiolus azoricus. BMC Genomics. 2010;11:e559.

10. Zheng P, Wang M, Li C, Sun X, Wang X, Sun Y, et al. Insights into deep-sea adaptations and host-symbiont interactions: a comparative transcriptome study on Bathymodiolus mussels and their coastal relatives. Mol Ecol. 2017;26:5133-48.

11. Holder T, Basquin C, Ebert J, Randel N, Jollivet D, Conti E, et al. Deep transcriptome-sequencing and proteome analysis of the hydrothermal vent annelid Alvinella pompejana identifies the CvP-bias as a robust measure of eukaryotic thermostability. Biol Direct. 2013;8:2.

12. Zhang Y, Sun J, Chen C, Watanabe HK, Feng D, Zhang Y, et al. Adaptation and evolution of deep-sea scale worms (Annelida: Polynoidae): insights from transcriptome comparison with a shallow-water species. Sci Rep. 2017;7:46205.

13. Lan Y, Sun J, Tian R, Bartlett DH, Li R, Wong YH, et al. Molecular adaptation in the world's deepest-living animal: insights from transcriptome sequencing of the hadal amphipod Hirondellea gigas. Mol Ecol. 2017;26:3732-43.

14. Hui M, Cheng J, Sha ZL. Adaptation to the deep-sea hydrothermal vents and cold seeps: insights from the transcriptomes of Alvinocaris longirostris in both environments. Deep Sea Res Part1 Oceanogr Res Pap. 2018;135:23-33.

15. Wong YH, Sun J, He LS, Chen LG, Qiu JW, Qian PY. High-throughput transcriptome sequencing of the cold seep mussel Bathymodiolus platifrons. Sci Rep. 2015:5:e16597.

16. Zhang J, Sun Q, Luan Z, Lian C, Sun L. Comparative transcriptome analysis of Rimicaris sp. reveals novel molecular features associated with survival in deep-sea hydrothermal vent. Sci Rep. 2017;7:2000.

17. Distel DL, Baco AR, Chuang E, Morrill W, Cavanaugh C, Smith CR. Do mussels take wooden steps to deep-sea vents? Nature. 2000;403:725-6.

18. Lorion J, Duperron S, Gros O, Cruaud C, Samadi S. Several deep-sea mussels and their associated symbi onts are able to live both on wood and on whale falls. Proc R Soc B. 2008;276:177-85.

19. Baba K, Williams AB. New Galatheoidea (Crustacea, Decapoda, Anomura) from hydrothermal systems in the West Pacific Ocean: Bismarck archipelago and Okinawa trough. Zoosystema. 1998;20:143-56.

20. Chan TY, Lee DA, Lee CS. The first deep-sea hydrothermal animal reported from Taiwan: Shinkaia crosnieri Baba and Williams, 1998 (Crustacea: Decapoda: Galatheidae). Bull Mar Sci. 2000;67:799-804.

21. Baba K, Macpherson E, Lin CW, Chan TY. Crustacean fauna of Taiwan: squat lobsters (Chirostylidae and Galatheidae). Keelung: National Taiwan Ocean University Press; 2009.

22. Shen $Y$, Kou $Q$, Chen W, He S, Yang M, Li X, et al. Comparative population structure of two dominant species, Shinkaia crosnieri (Munidopsidae: Shinkaia) and Bathymodiolus platifrons (Mytilidae: Bathymodiolus), inhabiting both deep-sea vent and cold seep inferred from mitochondrial multi-genes. Ecol Evol. 2016;6:3571-82.

23. Grabherr MG, Haas BJ, Yassour M, Levin JZ, Thompson DA, Amit I, et al. Fulllength transcriptome assembly from RNA-Seq data without a reference genome. Nat Biotechnol. 2011;29:644-52.

24. Pertea G, Huang XQ, Liang F, Antonescu V, Sultana R, Karamycheva S, et al. TIGR gene indices clustering tools (TGICL): a software system for fast clustering of large EST datasets. Bioinformatics. 2003;19:651-2.

25. Götz S, García-Gómez JM, Terol J, Williams TD, Nagaraj SH, Nueda MJ, et al. High-throughput functional annotation and data mining with the Blast2GO suite. Nucleic Acids Res. 2008:36:3420-35.

26. Moriya Y, Itoh M, Okuda S, Yoshizawa AC, Kanehisa M. KAAS: an automatic genome annotation and pathway reconstruction server. Nucleic Acids Res. 2007;35:182-5.

27. Edgar RC. MUSCLE: multiple sequence alignment with high accuracy and high throughput. Nucleic Acids Res. 2004;32:1792-7.

28. Guindon S, Dufayard J, Hordijk W, Lefort V, Gascuel O. New algorithms and methods to estimate maximum-likelihood phylogenies: assessing the performance of PhyML 3.0. Syst Biol. 2010;59:307-21.

29. Jensen JD, Bachtrog D. Characterizing recurrent positive selection at fastevolving genes in Drosophila miranda and Drosophila pseudoobscura. Genome Biol Evol. 2010;2:371-8.

30. Iseli C, Jongeneel CV, Bucher P. ESTScan: a program for detecting, evaluating, and reconstructing potential coding regions in EST sequences. Proc Int Conf Intell Syst Mol Biol. 1999;1999:138-48.

31. Li L, Stoeckert CJ, Roos DS. OrthoMCL: identification of ortholog groups for eukaryotic genomes. Genome Res. 2003;13:2178-89.

32. Yang Z, Nielsen R. Codon-substitution models for detecting molecular adaptation at individual sites along specific lineages. Mol Biol Evol. 2002;19:908-17.

33. Yang Z. PAML 4: phylogenetic analysis by maximum likelihood. Mol Biol Evol. 2007;24:1586-91.
34. Yang Z, Wong WS, Nielsen R. Bayes empirical bayes inference of amino acid sites under positive selection. Mol Biol Evol. 2005;22:1107-18.

35. Li B, Dewey CN. RSEM: accurate transcript quantifcation from RNA-Seq data with or without a reference genome. BMC Bioinformatics. 2011; 12:323.

36. Mortazavi A, Williams BA, Mccue K, Schaeffer L, Wold B. Mapping and quantifying mammalian transcriptomes by RNA-Seq. Nat Methods. 2008;5:621-8.

37. Anders $\mathrm{S}$, Huber $\mathrm{W}$. Differential expression analysis for sequence count data. Genome Biol. 2010;11:R106.

38. Dillies MA, Rau A, Aubert J, Hennequet-Antier C, Jeanmougin M, Servant N, et al. A comprehensive evaluation of normalization methods for Illumina highthroughput RNA sequencing data analysis. Brief Bioinform. 2013;14(6):671-83.

39. Benjamini $Y$, Hochberg Y. Controlling the fasle discovery rate: a practical and powerful approach to multiple testing. J R Stat Soc Ser B Methodol. 1995;57:289-300.

40. Young MD, Wakefield MJ, Smyth GK, Oshlack A. Method gene ontology analysis for RNA-seq: accounting for selection bias. Genome Biol. 2010;11:R14.

41. Benjamini Y, Hochberg Y. Controlling the false discovery rate: a practical and powerful approach to multiple testing. J R Stat Soc Series B. 1995;85:289-300.

42. Mao X, Cai T, Olyarchuk JG, Wei L. Automated genome annotation and pathway identification using the KEGG Orthology (KO) as a controlled vocabulary. Bioinformatics. 2005;21:3787-93.

43. Kolde R. Pheatmap: pretty heatmaps. 2015. https://cran.r-project.org/ web/packages/pheatmap/index.html. Accessed 14 May 2016.

44. Voolstra CR, Sunagawa S, Matz MV, Bayer T, Aranda M, Buschiazzo E, et al. Rapid evolution of coral proteins responsible for interaction with the environment. PLoS One. 2011;6:e20392.

45. Yang L, Wang Y, Zhang Z, He S. Comprehensive transcriptome analysis reveals accelerated genic evolution in a Tibet fish, Gymnodiptychus pachycheilus. Genome Biol Evol. 2015;7:251-61.

46. Teng L, Fan X, Xu D, Zhang X, Mock T, Ye N. Identification of genes under positive selection reveals differences in evolutionary adaptation between brown-algal species. Front Plant Sci. 2017;8:1429.

47. Wang XW, Luan JB, Li JM, Su YL, Xia J, Liu SS. Transcriptome analysis and comparison reveal divergence between two invasive whitefly cryptic species. BMC Genomics. 2011;12:458.

48. Roux J, Privman E, Moretti S, Daub JT, Robinson-Rechavi M, Keller L. Patterns of positive selection in seven ant genomes. Mol Biol Evol. 2014;31:1661-85.

49. Sen CK, Packer L, Hänninen O. Handbook of oxidants and antioxidants in exercise. Amsterdam: Elsevier; 2000.

50. Chaudhary M, Gupta R. Cyanide detoxifying enazyme: Rhodanese. Curr Biotechnol. 2012;1:327-35.

51. Veal EA, Toone WM, Jones N, Morgan BA. Distinct roles for glutathione S-transferases in the oxidative stress response in Schizosaccharomyces pombe. J Biol Chem. 2002;277:35523-31.

52. Hossain MD, Yamada N, Yamamoto K. Glutathione-binding site of a Bombyx mori theta-class glutathione transferase. PLoS One. 2014;9:e97740.

53. Rossjohn J, McKinstry WJ, Oakley AJ, Verger D, Flanagan J, Chelvanayagam G, et al. Human theta class glutathione transferase: the crystal structure reveals a sulfate-binding pocket within a buried active site. Structure. 1998;6:309-22.

54. Zhao ZY, Yin Z, Xu X, Weng S, Rao X, et al. A novel C-type lectin from the shrimp Litopenaeus vannamei possesses anti-white spot syndrome virus activity. J Virol. 2009;83:347-56.

55. Li FH, Xiang $\mathrm{JH}$. Recent advances in researches on the innate immunity of shrimp in China. Dev Comp Immunol. 2013;39:11-26.

56. Li Y, Yan J, Kim I, Liu C, Huo K, Rao H. Rad4 regulates protein turnover at a postubiquitylation step. Mol Biol Cell. 2010;21:177-85.

57. He X, Zhang P. Serine/arginine-rich splicing factor 3 (SRSF3) regulates homologous recombination-mediated DNA repair. Mol Cancer. 2015;14:158.

58. Harris CC. Structure and function of the p53 tumor suppressor gene: clues for rational cancer therapeutic strategies. J Natl Cancer Inst. 1996;88:1442-55.

59. Fei J, Kaczmarek N, Luch A, Glas A, Carell T, Naegeli H. Regulation of nucleotide excision repair by UV-DDB: prioritization of damage recognition to internucleosomal DNA. PLoS Biol. 2011;9:e1001183.

60. Camenisch U, Träutlein D, Clement FC, Fei J, Leitenstorfer A, Ferrando-May E, et al. Two-stage dynamic DNA quality check by xeroderma pigmentosum group C protein. EMBO J. 2009;28:2387-99.

61. Kantidze OL, Velichko AK, Luzhin AV, Razin SV. Heat stress-induced DNA damage. Acta Nat. 2016;8:75-8.

62. Morales ME, Derbes RS, Ade CM, Ortego JC, Stark J, Deininger PL, et al. Heavy metal exposure influences double strand break DNA repair outcomes. PLoS One. 2016;11:e0151367. 
63. Lushchak VI. Environmentally induced oxidative stress in aquatic animals. Aquat Toxicol. 2011;101:13-30.

64. Sharma P, Jha AB, Dubey RS, Pessarakli M. Reactive oxygen species, oxidative damage, and antioxidative defense mechanism in plants under stressful conditions. J Bot. 2012;217037:1-26.

65. Livingstone DR. Contaminant-stimulated reactive oxygen species production and oxidative damage in aquatic organisms. Mar Pollut Bull. 2001;42:656-66.

66. Valentine JS, Doucette PA, Zittin Potter S. Copper-zinc superoxide dismutase and amyotrophic lateral sclerosis. Annu Rev Biochem. 2005;74:563-93.

67. Lin YC, Vaseeharan B, Chen JC. Identifcation of the extracellular copper-zinc superoxide dismutase (ecCuZnSOD) gene of the mud crab Scylla serrata and its expression following beta-glucan and peptidoglycan injections. Mol Immunol. 2008;45:1346-55.

68. Sook Chung J, Bachvaroff TR, Trant J, Place A. A second copper zinc superoxide dismutase (CUZnSOD) in the blue crab Callinectes sapidus: cloning and upregulated expression in the hemocytes afer immune challenge. Fish Shellfsh Immunol. 2012;32:16-25.

69. Dickhout JG, Carlisle RE, Jerome DE, Mohammed-Ali Z, Jiang H, Yang G, et al. Integrated stress response modulates cellular redox state via induction of cystathionine $\gamma$-lyase: cross-talk between integrated stress response and thiol metabolism. J Biol Chem. 2012;287:7603-14.

70. Lee ZW, Low YL, Huang S, Wang T, Deng LW. The cystathionine $\gamma$-lyase/hydrogen sulfide system maintains cellular glutathione status. Biochem J. 2014;60:425-35.

71. Penning TM. Dihydrodiol dehydrogenase and its role in polycyclic aromatic hydrocarbon metabolism. Chem Biol Interact. 1993;89:1-34.

72. Burczynski ME, Lin HK, Penning TM. Isoform-specific induction of a human aldo-keto reductase by polycyclic aromatic hydrocarbons (PAHs), electrophiles, and oxidative stress: implications for the alternative pathway of PAH activation catalyzed by human dihydrodiol dehydrogenase. Cancer Res. 1999:59:607-14

73. Chen J, Adikari M, Pallai R, Parekh HK, Simpkins H. Dihydrodiol dehydrogenases regulate the generation of reactive oxygen species and the development of cisplatin resistance in human ovarian carcinoma cells. Cancer Chemother Pharmacol. 2008;61:979-87.

74. Sharma R, Yang Y, Sharma A, Awasthi S, Awasthi YC. Antioxidant role of glutathione S-transferases: protection against oxidant toxicity and regulation of stress-mediated apoptosis. Antioxid Redox Signal. 2004;6:289-300.

75. Shi $K$, Gao Z, Shi TQ, Song $P$, Ren LJ, Huang H, et al. Reactive oxygen species-mediated cellular stress response and lipid accumulation in oleaginous microorganisms: the state of the art and future perspectives. Front Microbiol. 2017;8:793.

76. Yang Y, Cheng JZ, Singhal SS, Saini M, Pandya U, Awasthi S, et al. Role of glutathione S-transferases in protection against lipid peroxidation. J Biol Chem. 2001;276:19220-30.

77. Jolly C, Morimoto RI. Role of the heat shock response and molecular chaperones in oncogenesis and cell death. J Natl Cancer Inst. 2000;92:1564-72.

78. Mogensen TH. Pathogen recognition and inflammatory signaling in innate immune defenses. Clin Microbiol Rev. 2009;22:240-73.

79. Rattanaporn O, Utarabhand P. Molecular cloning of a C-type lectin with two CRD domains from the banana shrimp Fenneropenaeus merguiensis: early gene upregulation after Vibrio harveyi infection. J Invertebr Pathol. 2011;106:196-204.

80. Wang XW, Wang JX. Pattern recognition receptors acting in innate immune system of shrimp against pathogen infections. Fish Shellfsh Immun. 2013;34:981-9.

81. Hoffmann JA, Kafatos FC, Janeway CA Jr, Ezekowitz RAB. Phylogenetic perspectives in innate immunity. Science. 1999:284:1313-8.

82. Medzhitov R, Janeway CA Jr. Decoding the patterns of self and nonselfby the innate immune system. Science. 2002;296:298-300.

83. Bohlson SS, Fraser DA, Tenner AJ. Complement proteins C1q and MBL are pattern recognition molecules that signal immediate and long-term protective immune functions. Mol Immunol. 2007;44:33-43.

84. Papareddy $P$, Kalle $M$, Kasetty G, Mörgelin M, Rydengård V, Albiger B, et al. C-terminal peptides of tissue factor pathway inhibitor are novel host defense molecules. J Biol Chem. 2010;285:28387-98.

85. Gorman MJ, Paskewitz SM. Serine proteases as mediators of mosquito immune responses. Insect Biochem Mol Biol. 2001;31:257-62.

86. Litman GW, Rast JP, Shamblott MJ, Haire RN, Hulst M, Roess W, et al. Phylogenetic diversifcation of immunoglobulin genes and the antibody repertoire. Mol Biol Evol. 1993;10:60-72.

87. Brites D, McTaggart S, Morris K, Anderson J, Thomas K, Colson I, et al. The Dscam homologue of the crustacean Daphnia is diversified by alternative splicing like in insects. Mol Biol Evol. 2008;25:1429-39.
88. Chou PH, Chang HS, Chen IT, Lin HY, Chen YM, Yang HL, et al. The putative invertebrate adaptive immune protein Litopenaeus vannamei Dscam (LvDscam) is the first reported Dscam to lack a transmembrane domain and cytoplasmic tail. Dev Comp Immunol. 2009;33:1258-67.

89. Zhang XW, Wang Y, Wang XW, Wang L, Mu Y, Wang JX. A C-type lectin with an immunoglobulin-like domain promotes phagocytosis of hemocytes in crayfsh Procambarus clarkii. Sci Rep. 2016;6:29924.

90. Rehman AA, Ahsan H, Khan FH. a-2-macroglobulin: a physiological guardian. J Cell Physiol. 2013;228:1665-75.

91. Chaikeeratisak V, Somboonwiwat K, Tassanakajon A. Shrimp Alpha-2macroglobulin prevents the bacterial escape by inhibiting fibrinolysis of blood clots. PLoS One. 2012;710:e47384.
Ready to submit your research? Choose BMC and benefit from:

- fast, convenient online submission

- thorough peer review by experienced researchers in your field

- rapid publication on acceptance

- support for research data, including large and complex data types

- gold Open Access which fosters wider collaboration and increased citations

- maximum visibility for your research: over $100 \mathrm{M}$ website views per year

At BMC, research is always in progress.

Learn more biomedcentral.com/submissions 